\title{
The Interaction of Hydrogen Ion, Carbon Dioxide and Potassium Ion in Controlling the Formation of Resistant Sporangia in Blastocladiella emersonii
}

\author{
BY D. H. GRIFFIN* \\ Botany Department, University of California, Berkeley, California, U.S.A.
}

(Received 9 October 1964)

\begin{abstract}
SUMMARY
Continuous culture and batch culture experiments on the control of morphogenesis of the aquatic phycomycete Blastocladiella emersonii led to the following conclusions: (1) The metabolism of Blastocladiella under the conditions of these experiments was highly oxidative, all of the substrate being accounted for as unused substrate, fungus-carbon and $\mathrm{CO}_{2}$. (2) Morphogenesis was dependent on potassium-ion concentration, ephemeral sporangiate organisms developed in low $\mathrm{K}^{+}$concentration and resistant sporangiate organisms developed in higher $\mathrm{K}^{+}$concentration. (3) Morphogenesis in these experiments was independent of $\mathrm{CO}_{2}$ partial pressure and $\mathrm{pH}$ value. (4) Morphogenesis was also dependent on an ionized species of carbonic acid (bicarbonate, carbonate) depending on the medium used. Ephemeral sporangia developed at low concentrations of these ions, $\mathrm{K}^{+}, \mathrm{HCO}_{3}{ }^{-}$and $\mathrm{CO}_{3}{ }^{2-}$, and resistant sporangia developed at higher concentrations. (5) The potassium and magnesium content and $\mathrm{pH}$ value of the organisms were independent of the $\mathrm{pH}$ value and potassium concentration of the medium over the ranges studied, and of the sporangium type produced by the organisms. The continuous culture apparatus used is described and continuous culture theory applicable to experiments in morphogenesis has been developed and tested.
\end{abstract}

\section{INTRODUCTION}

Blastocladiella emersonii Cant. \& Hyatt is an aquatic phycomycete in the order Blastocladiales. The organisms consist of two portions at maturity, a vegetative portion and a sporangium. The basal vegetative portion which bears rhizoids is separated by a septum from the terminal sporangium. The organisms are unbranched and produce only one sporangium. Two types of sporangia occur: (1) thin-walled hyaline ephemeral sporangia which discharge zoospores soon after formation; (2) thick-walled brown resistant sporangia which must age for several weeks before discharging zoospores. The symbols OC, ordinary colourless, for ephemeral sporangiate organisms and RS for resistant sporangiate, were used by Cantino (1961) and are used in the present paper in the same sense. The life-cycle of B. emersonii is of the brachyallomyces type; there is no evidence of syngamy or meiosis (Cantino, 1961). Thus the zoospores from either type of sporangium can develop into organisms which bear either type of sporangium. With this ambivalent behaviour it is clear that some factor or factors in the environment play a role in determining which

* Present address: Botany Department, University of Iowa, Iowa City, Iowa 52240. 
type of sporangium an individual zoospore will produce. Cantino (1961) studied the development of ephemeral and resistant sporangia by B. emersonii. He observed (Cantino, 1951) that zoospores widely spread on peptone agar grew into organisms bearing ephemeral sporangia. These organisms discharged zoospores that germinated in the surface water around the parent organism and grew to form a cluster of organisms. Within these clusters, and only there, did organisms with resistant sporangia develop. With sodium bicarbonate or calcium carbonate included in the medium, widely spread zoospores developed into resistant sporangiate (RS) organisms. From these observations Cantino (1951, p. 331) concluded that ' $\mathrm{CO}_{2}$ was indeed of fundamental importance in determining whether or not RS plants...were formed', and that the appearance of resistant sporangia in clusters of organisms was the result of local accumulation of carbon dioxide. Cantino (1951, p. 333) reported that 'a relatively small increase in available $\mathrm{CO}_{2}$...appeared to be necessary for the formation of individual RS plants', but (Cantino, 1951, p. 332) that 'inconsistent results were obtained with plates placed in gas chambers containing different quantities of $\mathrm{CO}_{2}$ ', and that (1951, pp. 333-335) 'extreme reduction of the atmospheric $\mathrm{CO}_{2}$ concentration often induced the formation of large quantities of RS...'. In these experiments no record was made of the $\mathrm{pH}$ values of the media.

Cantino (1956) presented further data about the relationship between $\mathrm{pH}$ value and bicarbonate effects on the formation of resistant sporangia. These experiments are difficult to interpret because bicarbonate concentration and hydrogen-ion concentration were varied simultaneously, and the experiments were made on agar media where the $\mathrm{pH}$ value and $\mathrm{CO}_{2}$ environment of the plants is difficult to determine accurately.

The differences in development of ephemeral sporangiate plants and resistant sporangiate plants are complex (Cantino, 1961) as one would expect for such a drastic difference in function. The short-lived ephemeral sporangiate plants are the rapidly reproducing portion of the life cycle and make their appearance when the environment has the proper conditions of nutrition, temperature, aeration, moisture, etc., for such growth. The resistant sporangium with its thick relatively impervious wall, lipid reserves and inactive metabolism allows Blastocladiella to survive adverse conditions. As the environment shifts from growth conditions to adverse conditions some factors characteristic of this change act on the developmental control machinery of the organism causing changes which result in the growth of a resistant sporangium. Since there are many ways in which an environment can become adverse, it is likely that there are many ways to affect the control mechanisms of the organism. One question is, what form of carbon dioxide is important? The carbon dioxide equilibrium with water is the crux of this question. The three variables, $\mathrm{pH}$ value, carbon dioxide concentration and bicarbonate concentration, at equilibrium are described by the Henderson-Hasselbalch equation. To determine which factor is important, two of the factors, e.g. carbon dioxide and bicarbonate must be varied over a wide range at each of several values of the third variable, the $\mathrm{pH}$ value. The environmental control necessary to do these experiments is difficult to attain in batch culture because the growing organisms make continuing changes in the culture as they grow: nutrients are used and metabolic products, including carbon dioxide, are formed, leading to changes in the hydrogen ion, bicarbonate ion and carbon dioxide concentrations. In continuous culture these variables can be 
precisely controlled because new medium is continuously fed into the culture and spent medium and organisms are continuously washed out. The growth rate and wash-out rate of the culture are so balanced in continuous culture that a steady state is achieved in which the concentrations of organisms, nutrients and metabolic products are all constant. Thus there need be no opportunity for alterations of $\mathrm{pH}$ value, bicarbonate or carbon dioxide concentrations because of the activities of the organism.

Continuous culture theory. Continuous culture theory has been developed (Monod, 1950; Novick \& Szilard, 1950) and tested experimentally (Herbert, Elsworth \& Telling, 1956). The theoretical treatment of continuous culture is dependent on the assumption that there is complete and instantaneous mixing of the contents of the culture such that the concentration of the components in the effluent is equal to their concentration in the vessel. The residence times of the components of the culture are determined by the ratio of the flow rate, $f$, to the volume of the vessel, $V$. This ratio is called the dilution rate, $D$. There are two sources of change in the concentration of organisms, $x$, the wash-out rate of the organisms by dilution of the culture,

and the growth of the organisms,

$$
-d x / d t=D x
$$

$$
d x / d t=\mu x .
$$

Equation (2) is the familiar logarithmic growth equation where $\mu$ is the specific growth constant.

During continuous culture, changes in the concentration of organisms are dependent on the balance between the growth rate and the wash-out rate,

$$
d x / d t=\mu x-D x .
$$

During a steady state $d x / d t$ is zero and therefore $D$ equals $\mu$.

One can calculate the length of time it takes for a zoospore to develop into a mature organism during steady-state growth with equation (4), where $\boldsymbol{P}_{M}$ is the number of mature organisms in the culture, $\boldsymbol{P}_{T}$ is the total number of organisms in the culture, $D$ is the dilution rate, and $G$ is the development time of the organisms:

$$
\boldsymbol{P}_{M} / \boldsymbol{P}_{r}=e^{-D a} \text {. }
$$

This equation is derived from the kineties of continuous culture theory. It is directly useful when the culture contains only ephemeral sporangiate Blastocladiella organisms.

To interpret the results of continuous culture experiments with Blastocladiella one would like to know the proportion of organisms in a culture which are developing resistant sporangia. Since there is a large difference in the development times of ephemeral- and resistant-sporangiate organisms, many which develop along the resistant sporangium pathway will be washed out of the culture before they reach a recognizable state of maturity, whereas most of the rapidly developing ephemeral sporangiate organisms will reach maturity in the culture tube. When the numbers of mature ephemeral and resistant sporangiate organisms are counted, the culture will have a disproportionate number of ephemeral sporangiate forms. By using equation (4) to solve simultaneously for the fraction of the total number of ephemeral and resistant sporangiate organisms that will reach maturity during their residence in the culture tube, one obtains equation (5), where $\boldsymbol{P}_{\mathrm{Rs}}$ and $\boldsymbol{P}_{\mathrm{oc}}$ are, 
respectively, the numbers of mature resistant sporangiate organisms and mature ephemeral sporangiate organisms, and $G_{\mathrm{RS}}$ and $G_{\mathrm{OC}}$ are, respectively, the development times in hours of the resistant and ephemeral sporangiate organisms, and $\rho_{\mathrm{Rg}}$ is the porportion of organisms which produce resistant sporangia:

$$
\rho_{\mathrm{RS}}=\frac{\left(\mathrm{P}_{\mathrm{RS}} / \boldsymbol{P}_{\mathrm{oc}}\right) \exp \left\{-\boldsymbol{D}\left(\boldsymbol{G}_{\mathrm{oC}}-\boldsymbol{G}_{\mathrm{RS}}\right)\right\}}{1+\left(\boldsymbol{P}_{\mathrm{Rs}} / \boldsymbol{P}_{\mathrm{oc}}\right) \exp \left\{-\boldsymbol{D}\left(\boldsymbol{G}_{\mathrm{oc}}-\boldsymbol{G}_{\mathrm{RS}}\right)\right\}} .
$$

Equation (5) takes into account the variation in dilution rates between cultures and the disparity in development times of the two kinds of sporangia when estimating the proportion of organisms which will develop resistant sporangia.

The results of the present paper support the hypothesis that a variety of factors can stimulate the formation of resistant sporangia. Resistant sporangium formation is stimulated by bicarbonate or carbonate ion, but these interact in some way with the yeast-extract peptone medium used. Potassium ion also stimulates the formation of resistant sporangia and this effect is independent of the bicarbonate effect and of differences in the yeast-extract peptone media.

\section{METHODS}

The strain of Blastocladiella emersonii used in these experiments was obtained from a subculture of Cantino's original isolate which has been maintained in the Berkeley Culture Collection since 1949.

Table 1. Compositions of culture media used

\begin{tabular}{|c|c|c|c|}
\hline \multicolumn{4}{|c|}{ PYG medium } \\
\hline Yeast extract (Difco) & $12.5 \mathrm{~g}$. & Tris (2-amino-2-hydroxymethyl- & \\
\hline Peptone (Difco) & $12.5 \mathrm{~g}$. & 1,3-propanediol) buffer & $6 \cdot 0 \mathrm{~g}$. \\
\hline Glucose & $30 \mathrm{~g}$. & De-ionized water & 101. \\
\hline \multicolumn{4}{|c|}{ PG/6 medium } \\
\hline Peptone (Difco) & $2 \cdot 0 \mathrm{~g}$ & Tris & $6 \cdot 0 \mathrm{~g}$. \\
\hline Glucose & $5 \cdot 0 \mathrm{~g}$. & De-ionized water & 101. \\
\hline \multicolumn{4}{|c|}{ Defined medium } \\
\hline Glucose & $10 \mathrm{~g}$. & Mn & 0.5 p.p.m \\
\hline L-glutamic acid & $10 \mathrm{~g}$. & $\mathrm{Zn}$ & 0.1 p.p.m \\
\hline DL-methionine & $0 \cdot 4 \mathrm{~g}$ & Mo & 0.2 p.p.m \\
\hline Thiamine.HCl & $200 \mu \mathrm{g}$ & Co & 0.2 p.p.m \\
\hline $\mathrm{KH}_{2} \mathrm{PO}_{4}$ & $10 \cdot 6 \mathrm{~g}$ & $\mathrm{Cu}$ & 0.1 p.p.m \\
\hline $\mathrm{K}_{2} \mathrm{HPO}_{4} \cdot 3 \mathrm{H}_{2} \mathrm{O}$ & $9 \cdot 6 \mathrm{~g}$. & $\mathrm{Ca}$ & 0.8 p.p.m \\
\hline $\mathrm{MgSO}_{4} \cdot 7 \mathrm{H}_{2} \mathrm{O}$ & $2 \cdot 0 \mathrm{~g}$ & B & 0.5 p.p.m \\
\hline Fe (versenol chelate)* & 0.3 p.p.m. & De-ionized water & 101. \\
\hline
\end{tabular}

* $\mathrm{Na}_{3}$-N-hydroxyethylethelenediaminetriacetate (Dow Chemical Co., Midland, Mich., U.S.A.)

The ingredients of the media used (defined medium, Barner \& Cantino, 1952; PYG; PG/6) are listed in Table 1. For all the media the glucose, the nitrogenous organic materials, the minerals, and the bulk of the water (about 9.5 l. after autoclaving) were autoclaved separately from each other. The $\mathrm{pH}$ values of the media were adjusted by adding $\mathrm{KOH}$ or $\mathrm{H}_{2} \mathrm{SO}_{4}$; the $\mathrm{K}+$ concentration was adjusted with $\mathrm{K}_{2} \mathrm{SO}_{4}$ except where noted in the results.

The culture apparatus (Fig. 1) (Griffin, 1962) was a modified version of that 
developed in the Bio-organic Chemistry Laboratory at Berkeley for the continuous culture of algae. The vessel consists of an outer tube $9 \mathrm{~cm}$. in diameter by about $70 \mathrm{~cm}$. long and an inner tube $7 \mathrm{~cm}$. in diameter by about $65 \mathrm{~cm}$. long projecting concentrically into the outer tube. The two tubes are sealed together at the top so there is a cylindrical space of about $1.5 \mathrm{~cm}$. between them. Both tubes taper conically at the bottom. The volume of the culture is about $600 \mathrm{ml}$. The inner tube,

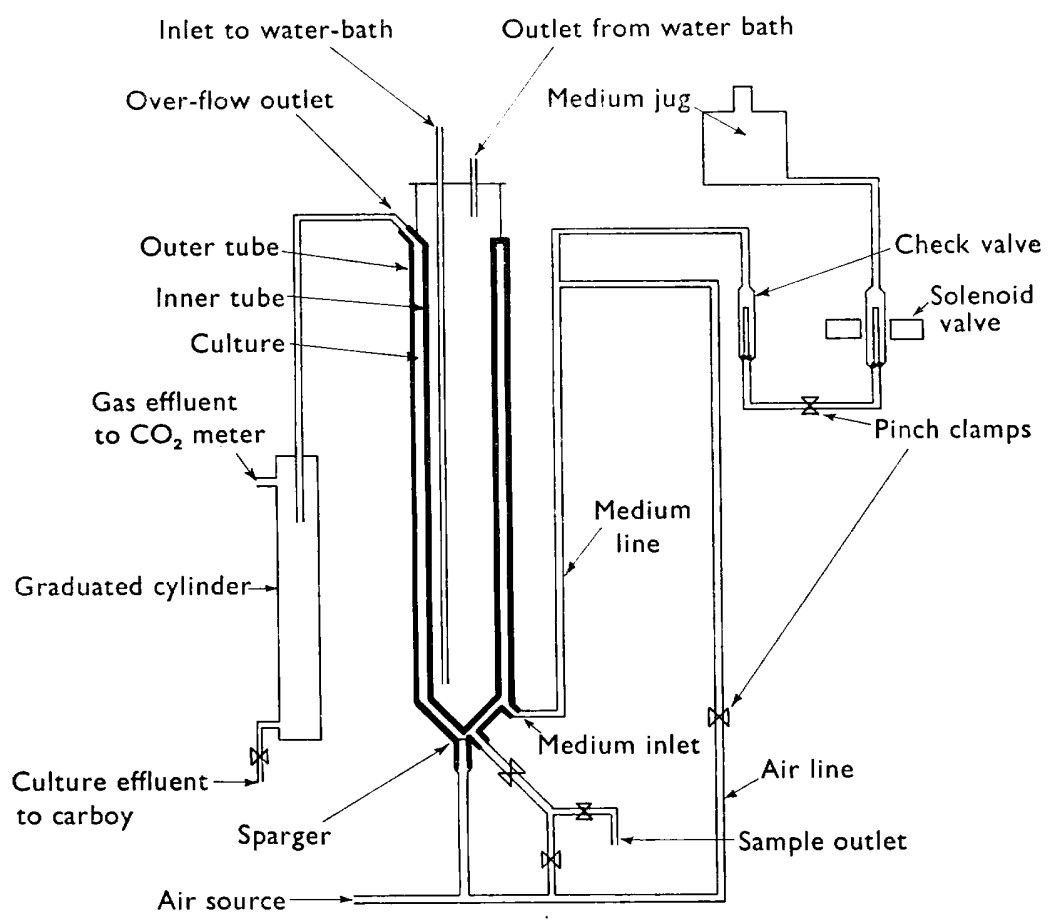

Fig. 1. Diagram of continuous culture apparatus.

closed at the bottom and open at the top, is a water bath through which water is circulated from a thermo-regulated water bath. The outer tube has an opening at the bottom through a ground glass joint wherein a sintered glass sparger mounted in the tip of the male portion of the ground glass joint is inserted. There are two openings in the side of the outer tube near the bottom, one for the medium inlet and one for withdrawing samples and inoculating the apparatus. The effluent opening is located at the top of the outer tube just below the ring-seal joining the inner and outer tubes at the top. The culture is contained in the space between the inner and outer tubes.

The flow rate of medium into the culture is controlled by a clock-operated solenoid valve. The back-up valve in the medium line prevents the culture from accidentally flowing into the medium jug. Air is slowly bled into the lower portion of the medium line to sweep it free from medium and to prevent zoospores from swimming up the medium line.

All experiments in the continuous culture apparatus were made at $25^{\circ}$ in light 
from G.E., cool white fluorescent bulbs. The intensity at the surface of the culture tube, measured by a Weston Foot Candle Meter was $600 \mathrm{ft}$.-c.

Inocula were prepared by growing cultures on medium PYG $+2 \%$ agar at room temperature (about $23^{\circ}$ ) for $15-24 \mathrm{hr}$, then flooding them for $5 \mathrm{~min}$. to $3 \mathrm{hr}$ with sterile dilute pond water ( 1 vol. filtered pond water +2 vol. distilled water; Emerson, 1958). The resulting suspension of zoospores was used to inoculate the cultures. At intervals after inoculation samples were withdrawn for observation. The $\mathrm{pH}$ value of the medium was determined with samples freshly aerated with effluent gas of the parent culture. The numbers of mature organisms were determined in samples containing 200 or more.

Glucose was measured by the method of Bernfeld (1955) and glutamic acid by the micro-Kjeldahl method. For mineral analyses the dry ashing procedure of Johnson \& Ulrich (1959) was used. After taking the ash up in $3 \mathrm{~N}-\mathrm{HCl}$ and filtering off unburned carbon, $\mathrm{K}^{+}$analyses were made with a Beckman DU Spectrophotometer equipped for flame photometry. A portion of the $\mathrm{HCl}$ solution was made up to $0 \cdot 1 \mathrm{~N}-\mathrm{HClO}_{4}$ and $5.7 \mathrm{~mm}-\mathrm{SrCl}_{2}$ for $\mathrm{Mg}^{2+}$ analyses in an atomic absorption spectrophotometer. Carbon dioxide analyses were done in a Liston-Becker infra-red analyser.

\section{RESULTS}

Carbon balance on a steady-state continuous culture

According to Cantino (1961, p. 246) 'The evidence suggests that a predominantly fermentative type of metabolism is involved. For example, a homolactic fermentation is demonstrable under certain conditions during growth.' The observations of Cantino \& Hyatt (1953) which showed the presence of the tricarboxylic acid cycle enzymes, and of Cantino \& Lovett (1960) which showed the high rate of endogenous $\mathrm{O}_{2}$ uptake by ephemeral sporangiate Blastocladiella organisms, are not compatible with this view. To help resolve this inconsistency a carbon balance on a steady-state continuous culture under aerobic conditions was made to determine whether the dissimilatory metabolism of Blastocladiella emersonii growing in defined medium had a fermentative or oxidative character. The rates of consumption of the carbon sources, glucose and glutamic acid, were correlated with the rates of production of fungus material and $\mathrm{CO}_{2}$. If the catabolism of the fungus was primarily fermentative, one would expect that only a small portion of the carbon consumed would be converted to fungus material; and in the case of a homolactic fermentation no $\mathrm{CO}_{2}$ would be produced. On the other hand, if the catabolism was principally oxidative, one would expect that up to $50 \%$ of the carbon consumed would be converted to fungus material (Foster, 1949) and the remainder to $\mathrm{CO}_{2}$.

Cultures were grown in defined medium (pH 7.5) in the continuous culture apparatus at $25^{\circ}$. The aeration rate was $0 \cdot 67 \mathrm{l} . / \mathrm{min}$. The inflowing gas was air containing 0.0005 atmosphere of $\mathrm{CO}_{2}$, and the effluent gas contained 0.0010 atmosphere of $\mathrm{CO}_{2}$. Glucose and glutamic acid analyses were made as described in Methods.

The data showing the rates of consumption of the carbon sources, glucose and glutamic acid, and the fate of this carbon as fungus material and $\mathrm{CO}_{2}$ are given in Table 2. Assuming the carbon content of the fungus to be $45 \%$ of the dry weight (Cochrane, 1958), the rate of incorporation of carbon into the fungus was calculated from the dry-weight data. As can be seen from Table 2, all the carbon taken from 
the medium was accounted for by fungus material $+\mathrm{CO}_{2}$. This is compatible with the hypothesis that under these particular conditions of nutrition and aeration, the metabolism of the Blastocladiella emersonii was largely oxidative and no lactic acid was produced. The conclusion that lactic acid was not produced is supported by the carbon balance and by there being no decrease in $\mathrm{pH}$ value. In several batch cultures with defined medium in the continuous culture apparatus, the $\mathrm{pH}$ value became more alkaline as the culture grew, also indicating that acid was not being produced. The data of Cantino \& Lovett (1960) which showed a high degree of lactic acid production may have been due to a lower degree of aeration than was maintained in the present experiments.

Table 2. Steady-state carbon balance of Blastocladiella growing in defined medium

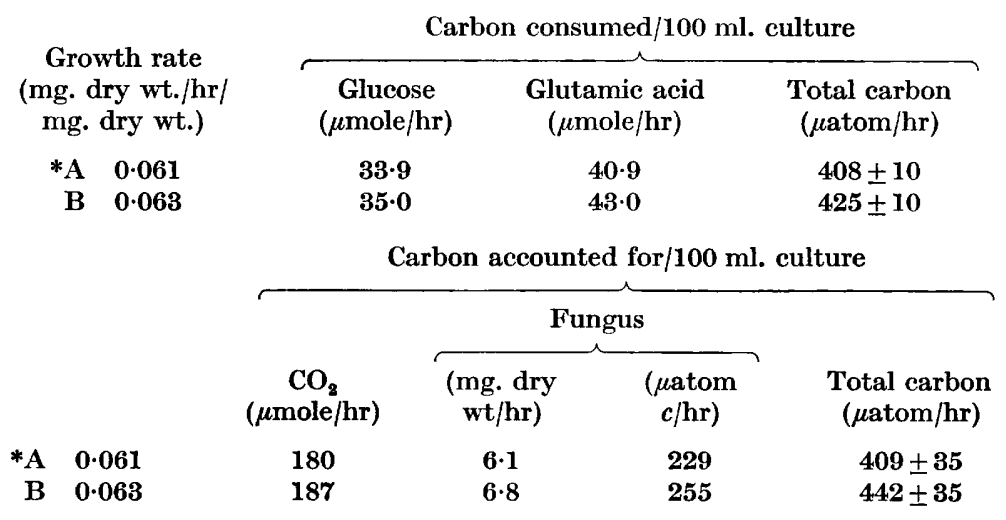

* Lines A refer to one determination; lines $\mathrm{B}$ refer to a second determination on the same steady state $10 \mathrm{hr}$ after the first.

\section{Growth of resistant sporangiate and ephemeral sporangiate Blastocladiella organisms in continuous culture}

The conditions under which resistant sporangiate, and ephemeral sporangiate, organisms developed were studied in continuous culture with medium PYG, and in batch culture with medium PG/6. The reasons for using different methods of cultivation for these two media are explained below. Other conditions and methods were as previously described.

Continuous culture experiments. Equation (5) was used to help interpret the results of these experiments by accounting for the differences in dilution rates between cultures and the differences in development times of ephemeral and resistant sporangiate organisms. The development time of an ephemeral sporangiate organism is the time for a zoospore to grow into an organism bearing a thin-walled colourless sporangium with cleaved-out zoospores. The development time of a resistant sporangiate organism is the time for a zoospore to grow into an organism bearing a pigmented thick-walled resistant sporangium.

The development times of ephemeral sporangiate blastocladiellas, $G_{0 \mathrm{oc}}$, were calculated from continuous culture data by using equation (4); the $G_{\mathrm{OC}}$ values varied from 13 to $19 \mathrm{hr}$ (Table 3). A burst of mature ephemeral sporangiate blastocladiellas was evident in all of the cultures within the first $24 \mathrm{hr}$. These were the first ephemeral 
sporangiate forms to mature from the inoculum and also gave a measure of the development time. These $G_{\mathrm{OO}}$ values are in general agreement with the development times reported by Cantino and co-workers: $12 \mathrm{hr}$ (McCurdy \& Cantino, 1960), 17-21 hr (Cantino \& Horenstein, 1959), 34 hr (Cantino, 1961).

In those cultures where a significant number of resistant sporangiate organisms developed, a burst of mature ephemeral sporangiate organisms occurred within the first $24 \mathrm{hr}$ after inoculation, indicating that the $G_{\mathrm{oc}}$ value was also of the order of $20 \mathrm{hr}$ in these cultures. Mature resistant sporangiate organisms began to appear in these cultures from 40 to $60 \mathrm{hr}$ after inoculation and gradually increased thereafter, indicating that the $G_{\mathrm{RS}}$ value for individual organisms was highly variable; but the average value was certainly longer than $60 \mathrm{hr}$. Cantino (1961) reported that the time for $5 \%$ of the RS organisms to mature averaged $108 \mathrm{hr}$.

Table 3. Development times of ephemeral sporangiate blastocladiellas in medium PYG; continuous culture

\begin{tabular}{|c|c|c|c|c|}
\hline $\begin{array}{c}\mathrm{pH} \\
\text { value }\end{array}$ & $\begin{array}{c}\mathrm{CO}_{2} \text { partial } \\
\text { pressure } \\
\left(\text { atm. } \times 10^{2}\right)\end{array}$ & $\begin{array}{c}\mathbf{K}^{+} \\
\text {concentration } \\
\text { (m-equiv./1.) }\end{array}$ & $\begin{array}{c}\text { Development } \\
\text { time } \\
\text { (hr) }\end{array}$ & $\underset{\left(h r^{-1}\right)}{D}$ \\
\hline $8 \cdot 1$ & $0 \cdot 05$ & $8 \cdot 0$ & 13 & $0 \cdot 10$ \\
\hline $7 \cdot 2$ & 4.0 & $8 \cdot 0$ & 16 & $0 \cdot 18$ \\
\hline $7 \cdot 2$ & 4.0 & $8 \cdot 0$ & 19 & $0 \cdot 15$ \\
\hline $7 \cdot 35$ & 0.05 & $8 \cdot 0$ & 19 & $0 \cdot 12$ \\
\hline
\end{tabular}

Table 4. The probability of a blastocladiella producing a resistant sporangium under various conditions of $\mathrm{H}^{+}, \mathrm{K}^{+}$and $\mathrm{CO}_{2}$ concentration* in continuous cultures, assuming $G_{\mathrm{OC}}=20 \mathrm{hr}$ and $G_{\mathrm{RS}}=100 \mathrm{hr}$

\begin{tabular}{|c|c|c|c|c|c|c|}
\hline $\begin{array}{c}\mathrm{pH} \\
\text { value }\end{array}$ & $\begin{array}{c}\mathrm{CO}_{2} \text { partial } \\
\text { pressure } \\
\left(\text { atm. } \times 10^{2}\right)\end{array}$ & $\begin{array}{c}\mathbf{K}^{+} \\
\text {concentra- } \\
\text { tion } \\
\text { (m-equiv./l.) }\end{array}$ & $\begin{array}{c}\mathbf{K}^{+} \\
\text {added as }\end{array}$ & $\begin{array}{c}D \\
\left(h r^{-1}\right)\end{array}$ & $\frac{\boldsymbol{P}_{\mathrm{RS}}}{\boldsymbol{P}_{\mathrm{RS}}+\boldsymbol{P}_{\mathrm{oO}}}$ & $\rho_{\mathrm{RS}}$ \\
\hline $8 \cdot 8$ & $0 \cdot 05$ & 8.0 & КОН & 0.048 & $0 \cdot 41$ & 0.97 \\
\hline $8 \cdot 1$ & $0 \cdot 4$ & $8 \cdot 0$ & КОH & 0.052 & 0.46 & 0.98 \\
\hline $7 \cdot 6$ & $4 \cdot 0$ & 27 & KOH & 0.047 & 0.98 & $1 \cdot 0$ \\
\hline $8 \cdot 0$ & 0.05 & 27 & $\mathrm{~K}_{2} \mathrm{SO}_{4}$ & 0.015 & 0.83 & $0 \cdot 94$ \\
\hline $7 \cdot 7$ & $0 \cdot 05$ & $28 \cdot 6$ & $\mathrm{KCl}$ & $0 \cdot 046$ & 0.92 & $1 \cdot 0$ \\
\hline $6 \cdot 7$ & 0.05 & 27 & $\mathrm{~K}_{2} \mathrm{SO}_{4}$ & 0.038 & $0 \cdot 83$ & 0.94 \\
\hline
\end{tabular}

* Two methods of stimulating resistant sporangium formation were used in these experiments, high $\mathrm{CO}_{3}{ }^{2-}$ and high $\mathrm{K}^{+}$concentration. These factors stimulate $\mathrm{RS}$ formation independently of each other.

The proportion of blastocladiellas producing resistant sporangia, $\rho_{\mathrm{RS}}$, in cultures containing resistant sporangiate organisms, was calculated by using equation (5) and $G_{\mathrm{OC}}$ values of $20 \mathrm{hr}$ and $G_{\mathrm{RS}}$ values of $100 \mathrm{hr}$. For comparison the ratio $\boldsymbol{P}_{\mathrm{RS}} /$ $\left(\boldsymbol{P}_{\mathrm{RS}}+\boldsymbol{P}_{\mathrm{OC}}\right)$ (the value of $\rho_{\mathrm{RS}}$ if one were to consider only the ratio of the number of favourable events to the total number of events without taking into account the variation in dilution rates between cultures and the disparity in the development times between the two types of blastocladiella) is shown in Table 4. 
The effect of potassium ion on the development of resistant sporangia

The effect of $\mathrm{K}^{+}$concentration on development of Blastocladiella in continuous culture is summarized in Table 5. Potassium at $27 \mathrm{~m}$-equiv./1. induced resistant sporangia. This effect was independent of $\mathrm{pH}$ value between $\mathrm{pH} 6 \cdot 7$ and $8 \cdot 0$, and also independent of the anion; $\mathrm{K}_{2} \mathrm{SO}_{4}$ and $\mathrm{KCl}$ at equivalent concentrations had the same effect. Batch culture experiments in medium PG/6 also showed that potassium ion induced the development of resistant sporangia. These experiments were performed as batch culture experiments because the growth rate of those cultures in which resistant sporangiate organisms developed was very slow and even the slowest dilution rate maintainable in continuous cultivation washed the culture out of the tube. This slow growth rate appeared to be the result of the small number of ephemeral sporangiate organisms in the culture rather than a change in the rate of development of ephemeral sporangiate organisms. Changes in $\mathrm{pH}$ value in batch cultures in medium PG/6 were generally less than $0 \cdot 1 \mathrm{pH}$ unit and often less than $0 \cdot 05$.

Table 5. The effects of $\boldsymbol{K}^{+}$on the formation of resistant sporangia in medium PYG; continuous culture

\begin{tabular}{|c|c|c|c|c|c|c|}
\hline $\begin{array}{c}\mathrm{pH} \\
\text { value }\end{array}$ & $\begin{array}{c}\mathrm{CO}_{\mathbf{2}} \\
\text { pressure } \\
\left(\mathrm{atm} . \times \mathbf{1 0}^{2}\right)\end{array}$ & $\begin{array}{c}\mathbf{K}^{+} \\
\text {concentra- } \\
\text { tion } \\
\text { (m-equiv./l.) }\end{array}$ & $\begin{array}{c}\mathbf{K}^{+} \\
\text {added as }\end{array}$ & $\underset{\text { (m-equiv./l.) }}{\mathrm{HCO}_{3}^{-}}$ & $\begin{array}{c}\mathrm{CO}_{3}^{2-} \\
\text { (m-equiv./l.) }\end{array}$ & $\begin{array}{c}\text { Kind of } \\
\text { sporangia } \\
\text { produced by } \\
c .100 \% \text { of } \\
\text { the organisms }\end{array}$ \\
\hline $7 \cdot 2$ & $0 \cdot 05$ & $8 \cdot 0$ & $\mathrm{~K}_{2} \mathrm{SO}_{4}$ & $0 \cdot 11$ & $0 \cdot 162$ & Ephemeral \\
\hline $8 \cdot 1$ & 0.05 & $8 \cdot 0$ & $\mathrm{~K}_{2} \mathrm{SO}_{4}$ & $0 \cdot 90$ & $10 \cdot 4$ & Ephemeral \\
\hline $7 \cdot 6$ & $4 \cdot 0$ & 27 & KOH & 23 & 80 & Resistant \\
\hline $8 \cdot 0$ & 0.05 & 27 & $\mathrm{~K}_{2} \mathrm{SO}_{4}$ & $0 \cdot 72$ & $6 \cdot 6$ & Resistant \\
\hline $7 \cdot 6$ & 0.05 & 27 & $\mathrm{KCl}$ & $0 \cdot 29$ & $1 \cdot 0$ & Resistant \\
\hline $6 \cdot 7$ & 0.05 & $32 \cdot 5$ & $\mathrm{~K}_{2} \mathrm{SO}_{4}$ & $0 \cdot 36$ & $0 \cdot 0138$ & Resistant \\
\hline
\end{tabular}

Table 6. The effect of $\mathrm{K}_{2} \mathrm{SO}_{4}$ on the formation of resistant sporangia in medium PG/6; batch cultures

\begin{tabular}{|c|c|c|c|c|}
\hline$\underset{\text { value }}{\mathbf{p H}}$ & $\begin{array}{c}\mathrm{CO}_{2} \text { partial } \\
\text { pressure } \\
\left(\text { atm. } \times 10^{2}\right)\end{array}$ & $\begin{array}{c}\mathrm{HCO}_{3}^{-} \\
\text {(m-equiv./l.) }\end{array}$ & $\begin{array}{c}\mathbf{K}^{+} \\
\text {(m-equiv./l.) }\end{array}$ & $\begin{array}{l}\text { Kind of sporangia } \\
\text { produced by } c .100 \% \\
\text { of the organisms }\end{array}$ \\
\hline $7 \cdot 9$ & $0 \cdot 05$ & 0.58 & $3 \cdot 4$ & Ephemeral \\
\hline $7 \cdot 95$ & 0.05 & $0 \cdot 6$ & 22 & $\begin{array}{l}\text { c. } 50 \% \\
\text { ephemeral } \\
\text { and } 50 \% \\
\text { resistant }\end{array}$ \\
\hline $7 \cdot 9$ & 0.05 & $0 \cdot 58$ & 28 & Resistant \\
\hline 7.95 & 0.05 & $0 \cdot 6$ & 34 & No growth \\
\hline $8 \cdot 85$ & 0.05 & $5 \cdot 0$ & 20 & No growth \\
\hline
\end{tabular}

In the batch culture experiments there were three types of results: (1) those cultures in which $\mathbf{4 0 - 7 0 \%}$ of the organisms developed ephemeral sporangia in about $20 \mathrm{hr}$ (designated OC cultures); (2) those cultures in which 1-10\% of the organisms developed ephemeral sporangia in $20 \mathrm{hr}$ and $10-30 \%$ of the organisms developed resistant sporangia in $\mathbf{8 0 - 1 0 0 ~ h r}$ (designated RS cultures); (3) those cultures in which less than 10 of the organisms developed ephemeral sporangia and less than two developed resistant sporangia in $\mathbf{1 0 0} \mathrm{hr}$ (designated as no growth). 
The effect of varying $\mathrm{K}_{2} \mathrm{SO}_{4}$ concentration is summarized in Table 6 . At a low $\mathrm{K}^{+}$ concentration (3.4 m-equiv./1.) ephemeral sporangiate organisms, and at a higher concentration (28 m-equiv./l.) resistant sporangiate organisms developed; above this latter concentration growth was inhibited. These experiments suggest that resistant sporangiate organisms were formed under particular stress conditions. They developed in a narrow zone between where ephemeral sporangiate organisms ceased to develop and where no growth occurred.

The effects of $\mathrm{pH}, \mathrm{CO}_{2}$ and $\mathrm{HCO}_{3}{ }^{-}$on the development of resistant sporangia

Experiments to determine the effect of $\mathrm{H}^{+}, \mathrm{CO}_{2}$ and $\mathrm{HCO}_{3}{ }^{-}$concentration on development were made in medium PYG. It was necessary to do these experiments in continuous culture in order to maintain a constant $\mathrm{pH}$ value, since the $\mathrm{pH}$ value of resistant sporangiate cultures changed rapidly in batch culture (see Table 9). These experiments, summarized in Table 7 , showed, under the conditions used, the following results :

(1) Control of development was independent of $\mathrm{CO}_{2}$ partial pressure since resistant sporangiate organisms and ephemeral sporangiate organisms both developed over the range of 0.0005 to 0.004 atmosphere $\mathrm{CO}_{2}$. (2) Control of development was independent of $\mathrm{pH}$ value since resistant sporangiate organisms and ephemeral sporangiate organisms both developed at the same $\mathrm{pH}$ value, $\mathrm{pH} \mathrm{8.1.} \mathrm{(3)} \mathrm{Control} \mathrm{of}$ development was independent of $\mathrm{HCO}_{3}{ }^{-}$concentration since resistant sporangiate cultures developed from 4.5 to $7 \cdot 2 \mathrm{~m}$-equiv./1. $\mathrm{HCO}_{3}{ }^{-}$, and ephemeral sporangiate cultures developed from $0 \cdot 11$ to $9 \cdot 2 \mathrm{~m}$-equiv./1. $\mathrm{HCO}_{3}{ }^{-}$. (4) Control of development was dependent on $\mathrm{CO}_{3}{ }^{2-}$ concentration since resistant sporangiate cultures developed above 80 m-equiv./1. $\mathrm{CO}_{3}{ }^{2-}$ and ephemeral sporangiate cultures developed below $12 \cdot 8 \mu$-equiv./1. $\mathrm{CO}_{3}^{2-}$.

Table 7. The effects of $\mathrm{pH}, \mathrm{CO}_{2}, \mathrm{HCO}_{3}-$ and $\mathrm{CO}_{3}{ }^{2-}$ on the formation of resistant sporangia in medium PYG; continuous culture

\begin{tabular}{|c|c|c|c|c|c|c|}
\hline$\underset{\text { value }}{\mathrm{pH}}$ & $\begin{array}{c}\mathrm{CO}_{2} \text { partial } \\
\text { pressure } \\
\left(\mathrm{atm} . \times 10^{2}\right)\end{array}$ & $\begin{array}{c}\mathbf{K}^{+} \\
\text {concentra- } \\
\text { tion } \\
\text { (m-equiv./l.) }\end{array}$ & $\begin{array}{c}\mathbf{K}^{+} \\
\text {added as }\end{array}$ & $\underset{\text { (m-equiv./l.) }}{\mathrm{HCO}_{3}^{-}}$ & $\underset{(\mu \text {-equiv./l.) }}{\mathrm{CO}_{3}{ }^{2-}}$ & $\begin{array}{c}\text { Kind of } \\
\text { sporangia } \\
\text { produced by } \\
\text { c. } 100 \% \text { of } \\
\text { the organisms }\end{array}$ \\
\hline $7 \cdot 2$ & 0.05 & $8 \cdot 0$ & $\mathrm{~K}_{2} \mathrm{SO}_{4}$ & $0 \cdot 11$ & $0 \cdot 162$ & Ephemeral \\
\hline $8 \cdot 1$ & 0.05 & $8 \cdot 0$ & $\mathrm{~K}_{2} \mathrm{SO}_{4}$ & 0.90 & $10 \cdot 4$ & Ephemeral \\
\hline $7 \cdot 2$ & $4 \cdot 0$ & $8 \cdot 0$ & $\mathrm{KOH}$ & $9 \cdot 2$ & $12 \cdot 8$ & Ephemeral \\
\hline $8 \cdot 8$ & 0.05 & $8 \cdot 0$ & КОН & 4.5 & 260 & Resistant \\
\hline $8 \cdot 1$ & $0 \cdot 4$ & $8 \cdot 0$ & $\mathbf{K O H}$ & $7 \cdot 2$ & 82 & Resistant \\
\hline
\end{tabular}

A similar series of experiments performed with medium PG/6 gave slightly different results. These were batch culture experiments, as previously described, and $\mathrm{pH}$ changes during a run were less than $0 \cdot 1 \mathrm{pH}$ unit. The results are summarized in Table 8 and indicate the following conclusions. (1) Control of development was independent of $\mathrm{pH}$ value since resistant sporangiate organisms developed from $\mathrm{pH}$ 6.7 to $8 \cdot 9$ and ephemeral sporangiate organisms developed from $\mathrm{pH} \mathbf{7 \cdot 1}$ to $\mathbf{7 \cdot 9}$. (2) Control of development was independent of $\mathrm{CO}_{2}$ partial pressure, although some $\mathrm{CO}_{2}$ was required for growth. Resistant sporangiate organisms developed in $0 \cdot 0005-$ $0 \cdot 10$ atmosphere $\mathrm{CO}_{2}$ and ephemeral sporangiate organisms developed in less than 
0.0001-0.01 atmosphere $\mathrm{CO}_{2}$. (3) Control of development was dependent on bicarbonate concentration, since resistant sporangiate plants developed between 5 and $8 \mathrm{~m}$-equiv./1. bicarbonate and ephemeral sporangiate plants developed at or below 2 m-equiv./. bicarbonate.

Table 8. The effects of $\mathrm{pH}, \mathrm{HCO}_{3}{ }^{-}$and $\mathrm{CO}_{2}$ on the formation of resistant sporangia in medium PG/6; batch cultures

\begin{tabular}{|c|c|c|c|c|c|}
\hline$\underset{\text { value }}{\mathrm{pH}}$ & $\begin{array}{c}\mathrm{CO}_{2} \text { partial } \\
\text { pressure } \\
\left(\text { atm. } \times \mathbf{1 0}^{2}\right)\end{array}$ & $\begin{array}{c}\mathrm{HCO}_{3}^{-} \\
\text {concentra- } \\
\text { tion } \\
\text { (m-equiv./l.) }\end{array}$ & $\begin{array}{c}\mathrm{CO}_{3}{ }^{2-} \\
\text { concentra- } \\
\text { tion } \\
(\mu \text {-equiv. } / \mathrm{l} .)\end{array}$ & $\frac{\mathbf{K}^{\dagger}}{\text { (m-equiv./l.) }}$ & $\begin{array}{l}\text { Kind of } \\
\text { sporangia } \\
\text { produced by } \\
c .100 \% \text { of } \\
\text { the organisms }\end{array}$ \\
\hline $7 \cdot 9$ & 0.05 & $0 \cdot 58$ & $4 \cdot 0$ & $3 \cdot 4$ & Ephemeral \\
\hline $7 \cdot 1$ & $1 \cdot 0$ & $1 \cdot 8$ & $2 \cdot 0$ & $3 \cdot 4$ & Ephemeral \\
\hline $7 \cdot 1$ & 0.05 & 0.09 & $1 \cdot 10$ & $3 \cdot 4$ & Ephemeral \\
\hline $8 \cdot 9$ & 0.05 & $5 \cdot 8$ & 400 & $3 \cdot 4$ & Resistant \\
\hline $7 \cdot 95$ & $0 \cdot 42$ & $4 \cdot 9$ & 32 & $3 \cdot 4$ & Resistant \\
\hline $7 \cdot 2$ & $4 \cdot 2$ & $8 \cdot 1$ & 13 & $3 \cdot 4$ & Resistant \\
\hline $6 \cdot 7$ & 10 & $7 \cdot 2$ & $0 \cdot 44$ & $3 \cdot 4$ & Resistant \\
\hline $8 \cdot 85$ & 0.00 & $0 \cdot 00$ & 0.00 & $3 \cdot 4$ & No growth \\
\hline $7 \cdot 9$ & 0.00 & 0.00 & $0 \cdot 00$ & $3 \cdot 4$ & No growth \\
\hline $7 \cdot 9$ & $<0.01$ & $<0.01$ & $<0.80$ & $2 \cdot 9$ & Ephemeral \\
\hline
\end{tabular}

The internal $p H$ value, $\mathrm{K}^{+}$content and $\mathrm{Mg}^{2+}$ content of ephemeral sporangiate and resistant sporangiate blastocladiellas grozen in single-generation batch cultures

The foregoing experiments showed that the external $\mathrm{K}^{+}$concentration and $\mathrm{pH}$ value, since concentration of ionized $\mathrm{CO}_{2}$ species are dependent on $\mathrm{pH}$ value, were important parameters in the morphogenesis of Blastocladiella emersonii. The following experiments were done to determine whether the internal $\mathrm{pH}$ value and $\mathrm{K}^{+}$ concentrations were correlated with resistant sporangium formation. Since $\mathrm{K}^{+}$ affects the uptake of the other major cation of the cell, $\mathrm{Mg}^{2+}$ (Rothstein, 1955, 1961), the cell content of $\mathrm{Mg}^{2+}$ was also measured. Sufficient material for analysis of resistant sporangiate cultures could not be obtained from continuous cultures. Therefore, single-generation cultures were grown in $10 \mathrm{l}$. of medium PYG in $20 \mathrm{l}$. carboys. The culture was inoculated with a suspension of zoospores prepared as previously described but standardized with a Klett-Summerson colorimeter so that $1.7 \times 10^{7}$ zoospores were inoculated into each $10 \mathrm{l}$. culture. The cultures were vigorously aerated with air blown through a bubbler tube. They were grown at $\mathbf{2 5}^{\circ}$ in dim light from G.E. white fluorescent bulbs at less than $1 \mathrm{ft}$.-c. at the surface of the carboys as measured by a Weston Foot Candle Meter. The results are given in Table 9. The results from OC cultures are the average of three replicates and the results from RS cultures are the average of two replicates. The oldest of the OC cultures contained about 5 of the organisms with cleaved or discharged zoospores. The RS cultures contained very few ephemeral sporangiate organisms; about half the organisms had reached maturity by $72 \mathrm{hr}$.

Table 9 shows no significant differences with respect to internal $\mathrm{pH}$ value, potassium content or magnesium content as between ephemeral sporangiate organisms (OC) and resistant sporangiate organisms (RS). There were differences between organisms grown under different conditions, but these differences were not 
correlated with the type of organism produced in the culture. The $\mathrm{pH}$ value of ephemeral sporangiate organisms varied from $\mathrm{pH} 6 \cdot 4$ to $7 \cdot 3$, and of resistant sporangiate organisms from $\mathrm{pH} 6 \cdot 5$ to $\mathbf{7 \cdot 0}$. The $\mathrm{K}^{+}$content of ephemeral sporangiate organisms varied from $21 \mathrm{~m}$-equiv./100 g. dry wt. organism to $41 \mathrm{~m}$-equiv./100 g. dry wt. organism; that of resistant sporangiate organisms varied from $14 \mathrm{~m}$-equiv./ $100 \mathrm{~g}$. dry wt. organism to $57 \mathrm{~m}$-equiv./100 g. dry wt. The $\mathrm{Mg}^{2+}$ content of ephemeral sporangiate organisms varied from $6 \cdot 4$ m-equiv./100 g. dry wt. organism to 15 m-equiv./100 g. dry wt.; that of resistant sporangiate organisms from $3 \cdot 2 \mathrm{~m}$-equiv./ $100 \mathrm{~g}$. dry wt. to $10 \mathrm{~m}$-equiv./100 g. dry wt.

Table 9. The internal $\mathrm{pH}, \mathrm{K}^{+}$and $\mathrm{Mg}^{2+}$ content of blastocladiellas grown in single generation batch cultures in medium $\mathbf{P Y G}$

\begin{tabular}{|c|c|c|c|c|c|c|c|}
\hline \multirow{3}{*}{$\begin{array}{l}\text { Time of } \\
\text { growth } \\
(\mathrm{hr})\end{array}$} & \multirow{3}{*}{$\begin{array}{c}\text { Initial } \\
\mathrm{pH} \\
\text { value }\end{array}$} & \multicolumn{2}{|c|}{ Medium } & \multicolumn{3}{|c|}{ Analysis of organisms } & \multirow{3}{*}{$\begin{array}{l}\text { Kind of } \\
\text { sporangia } \\
\text { produced by } \\
\text { c. } 100 \% \text { of } \\
\text { the plants }\end{array}$} \\
\hline & & \multirow{2}{*}{$\begin{array}{c}\text { Final } \\
\text { pH } \\
\text { value }\end{array}$} & \multirow{2}{*}{$\begin{array}{c}\mathrm{K}^{+} \\
\text {as } \mathrm{K}_{2} \mathrm{SO}_{4} \\
\text { m-equiv./l. }\end{array}$} & \multirow{2}{*}{$\begin{array}{l}\text { Internal } \\
\underset{\text { pH }}{\text { value }}\end{array}$} & \multicolumn{2}{|c|}{$\begin{array}{c}\text { Minerals } \\
\text { (m-equiv./100 } \mathrm{g} . \\
\text { dry wt.) }\end{array}$} & \\
\hline & & & & & $\mathbf{K}^{+}$ & $\mathrm{Mg}^{2+}$ & \\
\hline 13 & $7 \cdot 3$ & $7 \cdot 4$ & $8 \cdot 0$ & $6 \cdot 4$ & 21 & 15 & Ephemeral \\
\hline $17 \cdot 5$ & $7 \cdot 3$ & $7 \cdot 3$ & $8 \cdot 0$ & $6 \cdot 6$ & 22 & $6 \cdot 4$ & Ephemeral \\
\hline 12 & $6 \cdot 75$ & $6 \cdot 7$ & 8.0 & $7 \cdot 3$ & 35 & 8.9 & Ephemeral \\
\hline 16 & $6 \cdot 75$ & $6 \cdot 7$ & $8 \cdot 0$ & $7 \cdot 1$ & 41 & $10 \cdot 6$ & Ephemeral \\
\hline $\mathbf{2 4}$ & $7 \cdot 8$ & $7 \cdot 4$ & 27 & $7 \cdot 0$ & 51 & 10 & Resistant \\
\hline 48 & $7 \cdot 8$ & $7 \cdot 4$ & 27 & $7 \cdot 0$ & 20 & $4 \cdot 8$ & Resistant \\
\hline 72 & $7 \cdot 8$ & $7 \cdot 5$ & 27 & $7 \cdot 0$ & 14 & $5 \cdot 1$ & Resistant \\
\hline 24 & $7 \cdot 3$ & $7 \cdot 3$ & 27 & $6 \cdot 6$ & 57 & 10 & Resistant \\
\hline 48 & $7 \cdot 3$ & 6.5 & 27 & $6 \cdot 6$ & 28 & $3 \cdot 8$ & Resistant \\
\hline 72 & $7 \cdot 3$ & 6.5 & 27 & $6 \cdot 6$ & 31 & $5 \cdot 5$ & Resistant \\
\hline 24 & $8 \cdot 4$ & $7 \cdot 9$ & $8 \cdot 0$ & $6 \cdot 9$ & 28 & $7 \cdot 2$ & Resistant \\
\hline 48 & $8 \cdot 4$ & $7 \cdot 7$ & 8.0 & 6.9 & 17 & $3 \cdot 4$ & Resistant \\
\hline 72 & $8 \cdot 4$ & $6 \cdot 6$ & 8.0 & $6 \cdot 5$ & 23 & $3 \cdot 2$ & Resistant \\
\hline
\end{tabular}

\section{DISCUSSION}

The results show that several factors can influence resistant sporangium formation in Blastocladiella emersonii, namely, potassium ion, bicarbonate ion and carbonate ion. The latter two also appear to interact with a factor in yeast extract or peptone; however the potassium effect appears to be independent of this. One would like to know by what mechanisms these factors operate and whether they are affecting the same or closely related processes. The end product appears morphologically identical regardless of the set of conditions in which the resistant sporangiate organisms were grown. There are, doubtless, biochemical features common to resistant sporangiate organisms developing under different conditions. The known biochemical differences between ephemeral sporangiate organisms grown at a high $\mathrm{H}^{+}$and low $\mathrm{HCO}_{3}{ }^{-}$concentration, and resistant sporangiate organisms at low $\mathrm{H}^{+}$ and high $\mathrm{HCO}_{3}^{-}$, were summarized by Cantino (1961). There may also be other differences. Some, if not all, of these characteristics must be common to the particular developmental pathway regardless of the environmental factors which direct it. Thus, whether the concentration of potassium, bicarbonate or carbonate directs development, there is a common result, and these variables must act on the same initial components of the cell, those found in the young plants. 
Rothstein (1955) mentioned a number of interesting phenomena in his review on the effects of electrolytes on the metabolism of yeast. Potassium stimulates the fermentation of glucose without affecting respiration. This stimulation is dependent on the external $\mathrm{K}^{+}$concentration and is independent of internal concentration. The effect is not dependent on the simultaneous uptake of potassium. The effect is only on sugar metabolism and not on the metabolism of alcohol or endogenous substrates. Potassium not only affects the rate of fermentation but also changes the ratios of the products, glycerol, ethanol and carbon dixoide, and inhibits the production of polysaccharide, a by-product of metabolism. These effects of $\mathrm{K}^{+}$concentration are $\mathrm{pH}$ dependent. In the absence of potassium the rate of sugar fermentation shows a bimodal dependence on $\mathrm{pH}$ with optima at $\mathrm{pH} 4.5$ and 8.5 . In high $\mathrm{K}^{+}$concentration the curve becomes flat over the range of $\mathrm{pH} 2$ to 10 . The internal $\mathrm{pH}$ as measured by the freeze-thaw technique of Conway \& Downey (1950) is constant over this external $\mathrm{pH}$ range. Rothstein (1955) interpreted these data as an effect of potassium at the cell surface on the metabolism of the cell but the mechanism of action has not yet been explained.

There are certain interesting parallels between the yeast story and the effects observed with Blastocladiella emersonii, namely, the internal $\mathrm{pH}$ of the blastocladiellas is not correlated with the external $\mathrm{pH}$ and the internal $\mathrm{K}^{+}$concentration is not correlated with the external concentration over the ranges studied. Perhaps the effect of $\mathrm{K}^{+}$in directing the development of $\boldsymbol{B}$. emersonii is also at the cell surface. It is possible that the effects of $\mathrm{HCO}_{3}{ }^{-}$and $\mathrm{CO}_{3}{ }^{2-}$ have a similar explanation. Cantino (1961) stated that bicarbonate acts as a $\mathrm{CO}_{2}$ source, reversing the decarboxylation steps centring around $\alpha$-ketoglutarate in a weakly functional TCA cycle. One would expect that an increase in free $\mathrm{CO}_{2}$ would be more effective than increasing the bicarbonate concentration in equilibrium with the $\mathrm{CO}_{2}$. The data from the batch culture experiments in medium PG/6 and the continuous culture experiments in medium PYG are against the hypothesis that bicarbonate acts as a source of free $\mathrm{CO}_{2}$, since it was shown that the partial pressure of $\mathrm{CO}_{2}$ itself was unimportant in determining the development of the blastocladiellas. The carbon balance and the difficulties in sweeping out the metabolic $\mathrm{CO}_{2}$ in the ' $\mathrm{CO}_{2}$-free' cultures also suggest that $B$. emersonii has a strong $\mathrm{CO}_{2}$-forming metabolism rather than a homolactic fermentation. Furthermore, if it can be assumed that unhydrated $\mathrm{CO}_{2}$ molecules are freely diffusable through a cell membrane (as supported by Conway \& Downey, 1950), then the internal $\mathrm{pH}$ value of a cell under known partial pressures of $\mathrm{CO}_{2}$ determines the internal bicarbonate concentration and thus the total $\mathrm{CO}_{2}$ content. The internal $\mathrm{pH}$ of ephemeral sporangiate blastocladiellas grown at $\mathrm{pH} 6.7$ was higher than that of resistant sporangiate organisms grown at $\mathrm{pH} \mathbf{8 . 4}$. Thus the internal $\mathrm{pH}$ value and presumably the internal bicarbonate concentration are not correlated with the external values, and they are just the opposite of what one would expect for bicarbonate to act directly inside the cell in the manner postulated by Cantino. Thus the effects of $\mathrm{HCO}_{3}{ }^{-}$and $\mathrm{CO}_{3}{ }^{2-}$ may also be at the cell surface. However, if the primary effect is at the cell surface, it is also transmitted to the internal machinery of the cell to act on such mitochondrial constituents as succinic dehydrogenase and cytocrhome oxidase (Cantino, 1961).

One of the principal difficulties yet to be overcome in the study of development of resistant sporangia and ephemeral sporangia of Blastocladiella emersonii is the 
inability to obtain resistant sporangia in a defined medium. This, coupled with the difference between cultures grown in media PYG and PG/6, suggests that some unknown factor in the peptone and yeast extract is playing a central role in the formation of resistant sporangia. Understanding the nature of this factor will lead to further insight into the machinery of the control of morphogenesis in B. emersonii.

The helpful advice of Drs R. Park and R. Emerson and the use of the facilities of the Bio-organic Chemistry Laboratory are gratefully acknowledged.

\section{APPENDIX}

Continuous culture theory. This treatment depends on the assumptions that dilution is continuous and that there is complete and instantaneous mixing of the inflowing medium with the culture contents.

A given concentration of blastocladiellas, $\boldsymbol{P}_{\boldsymbol{r}}$, at any time, $t$, under a constant dilution rate will be washed out at the rate

Integration of equation (6) yields

$$
-d P_{T} / d t=D P_{T}
$$

$$
P_{r}=P_{\text {zoosp }} e^{-D t}
$$

where $\boldsymbol{P}_{\text {zoosp }}$ is the initial concentration of zoospores inoculated into the apparatus and $\boldsymbol{P}_{t}$ is the concentration of growing blastocladiellas in the apparatus after dilution for $t$ hours since inoculation. When these blastocladiellas are releasing zoospores, $t=G$, the development time, and there will be $P_{G}$ blastocladiellas in the culture according to equation (8),

$$
P_{G}=P_{\text {zoosp }} e^{-D G} \text {. }
$$

Under conditions of steady-state growth with a multi-generation culture it is not possible to follow a single set of zoospores. Since the growth rate of the culture is constant, the number of zoospores, $\boldsymbol{P}_{z}$, is constant. All mature blastocladiellas $=G \mathrm{hr}$ old. Let $Q=$ the number of hours older than $G$ any particular mature blastocladiella is. Then the number of mature blastocladiellas, $P_{\text {mature }}, G+Q$ hours old is

$$
\boldsymbol{P}_{\text {mature }}=\boldsymbol{P}_{z} e^{D-(\theta+Q)}
$$

The total number of mature blastocladiellas, $\boldsymbol{P}_{M}$, is given by

and

$$
\boldsymbol{P}_{\mathbf{M}}=\int_{0}^{\infty} \boldsymbol{P}_{z} e^{-D(G+Q)} d \boldsymbol{Q},
$$

$$
\boldsymbol{P}_{\boldsymbol{M}}=\left(\boldsymbol{P}_{z} / \boldsymbol{D}\right) e^{-D G} .
$$

All immature plants are $<G$ hours old. Let $R=$ the age of any immature plant. $R$ may take values from 0 to $G$. The number of immature blastocladiellas, $P_{\text {Immature, }}$ at some age, $R$, is

$$
P_{\text {immature }}=\boldsymbol{P}_{z} e^{-D R} \text {. }
$$

The total number of immature blastocladiellas, $P_{i}$, is given by

and

$$
P_{i}=\int_{0}^{G} P_{z} e^{-D R} d R
$$


Dividing equation (14) by equation (11) and rearranging gives

$$
\boldsymbol{P}_{\boldsymbol{M}} /\left(\boldsymbol{P}_{\boldsymbol{M}}+\boldsymbol{P}_{i}\right)=e^{-D \theta} \text {. }
$$

Since $\boldsymbol{P}_{\boldsymbol{i}}+\boldsymbol{P}_{\boldsymbol{M}}=\boldsymbol{P}_{\boldsymbol{T}}$, equation (15) can be written

$$
\boldsymbol{P}_{M} / \boldsymbol{P}_{\boldsymbol{T}}=e^{-D \theta},
$$

which is identical to equation (4). The logarithmic form (equation (17)) of equation (16) is used for ease of calculation,

$$
\boldsymbol{G}=D^{-1} \ln \left(\boldsymbol{P}_{\boldsymbol{r}^{\prime}} / \boldsymbol{P}_{M}\right) .
$$

If one knows the development times of ephemeral sporangiate blastocladiellas and resistant sporangiate blastocladiellas, the probability of a zoospore developing into a resistant sporangiate glastocladiella can be calculated from the ratio of mature resistant sporangiate blastocladiellas to mature ephemeral sporangiate blastocladiellas.

For the case where resistant sporangiate blastocladiellas and ephemeral sporangiate blastocladiellas both occur in the same culture, equation (16) can be rewritten into two simultaneous equations (equations (18) and (19)), where $\boldsymbol{P}_{R S}$ is the number of mature resistant sporangiate blastocladiellas, $T_{R S}$ is the total number of blastocladiellas developing along the resistant sporangial pathway, and $G_{R S}$ is the development time of a resistant sporangiate blastocladiella. The subscript $\mathrm{OC}$ refers to the corresponding values for ephemeral sporangiate blastocladiellas,

$$
\begin{aligned}
& P_{\mathrm{RS}} / T_{\mathrm{RS}}=\exp \left\{-D G_{\mathrm{RS}}\right\}, \\
& P_{\mathrm{OO}} / T_{\mathrm{OC}}=\exp _{\text {exp }}\left\{-D G_{\mathrm{OC}}\right\} .
\end{aligned}
$$

The total number of blastocladiellas, $T P 1$, is given by

$$
T_{p 1}=T_{\mathrm{Rg}}+T_{\mathrm{oc}}
$$

Therefore the probability of a zoospore developing into a resistant sporangiate blastocladiella, $\rho_{\mathrm{RS}}$, is

$$
T_{\mathrm{RS}} / T_{p 1}=\rho_{\mathrm{RS}}
$$

By combining equations (18), (19) and (21) and making the proper rearrangements one gets equation (22),

$$
\rho_{\mathrm{RS}}=\frac{\left(\boldsymbol{P}_{\mathrm{RS}} / \boldsymbol{P}_{\mathrm{oO}}\right)_{\exp }\left\{-D\left(\boldsymbol{G}_{\mathrm{OC}}-\boldsymbol{G}_{\mathrm{RS}}\right)\right\}}{1+\left(\boldsymbol{P}_{\mathrm{RS}} / \boldsymbol{P}_{\mathrm{OC}}\right)_{\mathrm{exp}}\left\{-\boldsymbol{D}\left(\boldsymbol{G}_{\mathrm{OC}}-\boldsymbol{G}_{\mathrm{RS}}\right)\right\}} .
$$

If $G_{\mathrm{OC}}=G_{\mathrm{RS}}$, then equation (22) reduces to

$$
\rho_{\mathrm{RS}}=\boldsymbol{P}_{\mathrm{KS}} /\left(\boldsymbol{P}_{\mathrm{OC}}+\boldsymbol{P}_{\mathrm{RS}}\right) \text {. }
$$

Inspection of equation (22) shows that for a given $\rho_{\mathrm{Rs}}$, when $\boldsymbol{G}_{\mathrm{oc}}=\boldsymbol{G}_{\mathrm{RS}}$, the observed ratio of mature resistant sporangia to ephemeral sporangia is highly dependent on the dilution rate. Therefore, comparison of results between cultures based on the ratio $\boldsymbol{P}_{\mathrm{RA}} / \boldsymbol{P}_{\mathrm{OC}}$ is only valid when the dilution rates of the cultures are all identical. Use of equation (22) eliminates the necessity of precisely duplicating dilution rates in different cultures. 


\section{REFERENCES}

Banner, H. D. \& Cantino, E. C. (1952). Nutritional relationships in a new species of Blastocladiella. Am. J. Bot. 39, 746.

Bernifed, P. (1955). Amylases, $\alpha$ and $\beta$. Meth. Enzymol. 1.

Cantino, E. C. (1951). Metabolism and morphogenesis in a new Blastocladiella. Antonie. van Leeuwenhoek, 17, 325.

Cantino, E. C. (1956). The relation between cellular metabolism and morphogenesis in Blastocladiella. Mycologia, 48, 225.

Cantino, E. C. (1961). The relation between biochemical and morphological differentiation in nonfilamentous aquatic fungi. Microbial reaction to environment. In Symp. Soc. gen. Microbiol. 11, 243.

Cantino, E. C. \& Horenstein, E. A. (1959). The stimulatory effect of light upon growth and $\mathrm{CO}_{2}$ fixation in Blastocladiella. III. Further studies, in vivo and in vitro. Physiol. Plant. 12, 251.

Cantino, E. C. \& Hyatr, M. T. (1953). Further evidence for the role of the tricarboxylic acid cycle in morphogenesis in Blastocladiella emersonii. J. Bact. 66, 712.

Cantino, E. C. \& LovetT, J. S. (1960). Respiration of Blastocladiella during bicarbonateinduced morphogenesis in synchronous culture. Physiol. Plant. 13, 450.

Cochrane, V. W. (1958). Physiology of the Fungi. New York: John Wiley and Sons Inc.

Conway, E. J. \& Downey, M. (1950). pH values of the yeast cell. Biochem. J. 47, 355.

Emerson, R. (1958). Mycological organization. Mycologia, 50, 589.

Foster, J. W. (1949). Chemical Activities of Fungi. New York: Academic Press.

Griffin, D. H. (1962). Development of water molds in continuous culture. (Abstr.) Am. J. Bot. 49, 666.

Herbert, D., Elsworth, R. \& Telling, R. C. (1956). The continuous culture of bacteria; a theoretical and experimental study. J. gen Microbiol. 14, 601.

Johnson, C. M. \& Ulrich, A. (1959). Analytical methods for use in plant analysis. Calif. Agric. Exp. Sta. Bull. 766, 26.

McCurdy, H. D. Jr. \& Cantino, E. C. (1960). Isocitritase, glycine-alanine transaminiase, and development in Blastocladiella emersonii. Plant Physiol. 35, 463.

Monod, J. (1950). La technique de culture continué; théorie et applications. Annls. Inst. Pasteur, Paris, 79, 390.

Novick, A. \& Szrlard, L. (1950). Experiments with the chemostat on spontaneous mutations of bacteria. Proc. natn. Acad. Sci., U.S.A., 36, 708.

Rothstein, A. (1955). Relationship of the cell surface to electrolyte metabolism in yeast. In Electrolytes in Biological Systems. Ed. by A. Shanes. Washington: Amer. Physiol Soc.

Rothstern, A. (1961). Interrelationships between the ion transporting systems of the yeast cell. In Membrane Transport and Metabolism. Ed. by A. Kleinzeller and A. Kotyk. London: Academic Press. 